\title{
Dyke-Davidoff-Masson Syndrome
}

\author{
Kalyan Paudel, ${ }^{1}$ Anand Venugopal ${ }^{2}$ \\ 'Kathmandu Model Hospital and Medicare National Hospital, Kathmandu, Nepal, ${ }^{2}$ Kasturba Medical College, Manglore, \\ India.
}

\section{ABSTRACT}

Dyke-Davidoff-Masson syndrome refers to atrophy of one cerebral hemisphere (hemiatrophy) due to an insult to the brain in fetal or early childhood period. This is an uncommon condition. We present a case of a nine month- old female presented with seizure and weakness of the right upper and lower extremities and subsequently computed tomography was performed and showed hemiatrophy of the left fronto-parietal lobe with degenerative changes in the left cerebral peduncle.

Keywords: Dyke-Davidoff-Masson syndrome; hemiatrophy; hemiplegia.

\section{INTRODUCTION}

Dyke-Davidoff-Masson syndrome (DDMS) is a congenital, neonatal or early infantile condition characterized clinically by variable degrees of facial asymmetry, seizures, contralateral hemiplagia or hemiparesis, and mental retardation. ${ }^{1}$ This is an uncommon condition, which is diagnosed with typical clinical features (seizures, hemipleagia or hemiparesis and mental retardation) and Computed Tomography (CT) or Magnetic Resonance Imaging (MRI) findings. This uncommon condition has been reported in a few international journals.

\section{CASE REPORT}

A nine moth old female presented to the pediatric OutPatient Department (OPD) with complaints of seizure and weakness of right upper and lower limbs for three months. Seizures occurred occasionally and lasted for seconds to minutes. She was born by vaginal delivery at term weighing $2.5 \mathrm{~kg}$ at birth. She had a history of meconium aspiration for which she was admitted to the intensive care unit (ICU) for five days. On examination, the vitals were within normal limits. Muscular rigidity and hyperreflexia were noted in the right upper and lower limbs. She had no obvious facial asymmetry or skin lesions. Blood studies were within normal limits. A plain and contrast enhanced CT was performed which revealed hemiatrophy of the left fronto-parietal lobe with ipsilateral prominent cortical sulci and left lateral ventricle (Figure 1). There were also wallerian degenerative changes in the left cerebral peduncle (Figure 2). Based on clinical features and CT findings diagnosis of DDMS was made. 


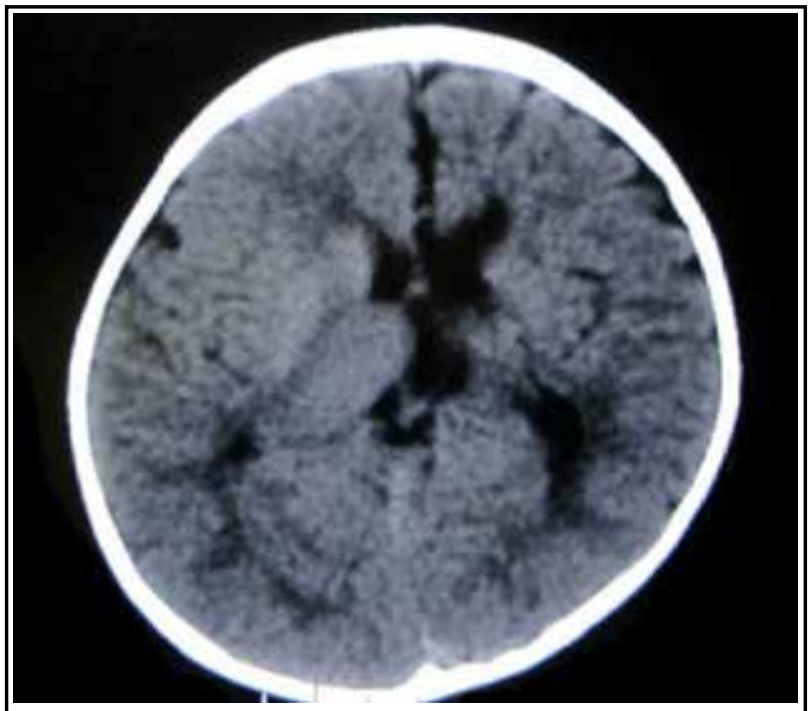

Figure 1. Plain CT head showing left fronto-parietal cerebral hemiatrophy with dilated ipsilateral lateral ventricle and widened cortical sulci.

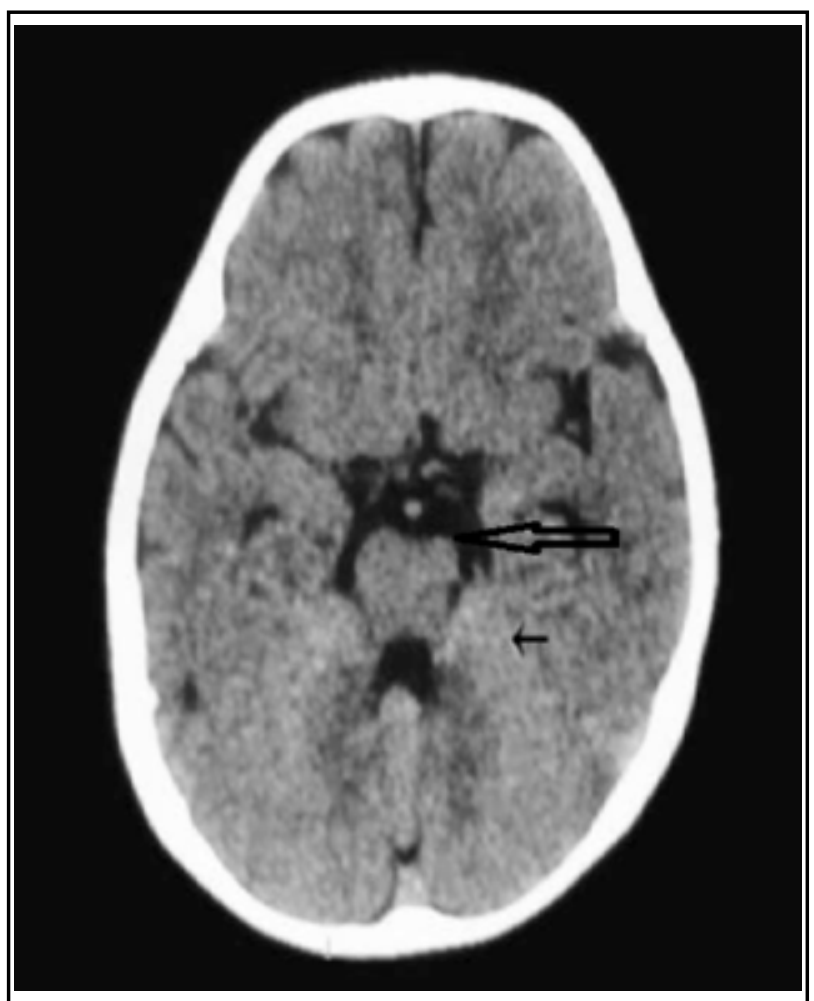

Figure 2. Plain CT head shows secondary wallerian degenerative changes in the left cerebral peduncle (demonstrated by wide arrow). Note the thin arrow points to the left cerebellum.

\section{DISCUSSION}

DDMS is an uncommon condition which is diagnosed with typical clinical features (seizures, hemipleagia or hemiparesis and mental retardation) and CT or MRI findings. However, mental retardation is not always present and seizure may appear months or years after the onset of hemiparesis or hemiplegia. ${ }^{2}$ Dyke, Davidoff and Masson first described this rare condition in 1933. They reported a series of nine patients with hemiplegia who had cranial asymmetry on plain skull radiographs. ${ }^{3}$

The various causes of cerebral hemiatrophy may be classified into two groups: congenital or acquired. In the congenital type, cerebral damage, which usually has a vascular origin, occurs during intrauterine life and symptoms appear at birth or shortly thereafter. ${ }^{1}$ In the acquired type, the symptoms are related to central nervous system damage that occurs in perinatal period or later. ${ }^{2}$ The etiological factors involved are trauma, infection, and vascular abnormalities of the cerebral circulation, ischemic and hemorrhagic conditions. ${ }^{2,4}$ The mechanism of cerebral atrophy is still unclear, but it is hypothetised that ischemic episodes from a variety of different causes reduce the production of brain derived neutrophic factors, which in turn lead to cerebral atrophy. ${ }^{5}$

Plain radiograph of skull may show ipsilateral calvarial thickening with loss of convolutional markings of the inner table, hyperpneumatization of the paranasal sinuses and mastoid air cells. ${ }^{1}$ CT findings are characteristic and shows cerebral hemiatrophy with prominent lateral ventricle and cortical sulci on the affected side. In addition, CT also demonstrates the plain radiographic findings such as calvarial thickening and hyperpneumatization of paranasal sinuses. However, in our patient, calvarial thickening was absent. The hemiatrophic cerebral parenchyma will have prominent sulci if the vascular insult occurs after birth; if the vascular ischemia occurs during embryogenesis, no prominent sulci will be present. ${ }^{1}$ In our patient, widened sulci reflect late onset brain insults, which were the consequences of meconium aspiration syndrome during postnatal period.

MRI is the imaging modality of choice to assess the cause and area of involvement of cerebral hemispheres. Cerebral angiography may show attenuated small vessels on the ipsilateral side, but that finding does not necessarily imply a primary vascular occlusive etiology. ${ }^{6}$ Brain SPECT may show a decreased volume of the involved part of the brain with reduced blood flow.

Differential diagnosis of cerebral hemiatrophy includes Sturge-Weber syndrome and conditions that are associated with unilateral megalencephaly. The characteristic clinical feature of port-wine strain and the imaging features of cortical atrophy and tram track calcifications help to detect Sturge Weber syndrome. Hemimegalencephaly is a congenital malformation 
in which defective cellular organization and neuronal migration results in hamartomatous overgrowth of a hemisphere. ${ }^{7}$ Intractable seizures in the first year of life progress to contralateral hemiparesis in this condition. ${ }^{7}$ Imaging features include an enlarged dysplastic hemisphere and enlarged ipsilateral lateral ventricle and thickened hemicranium. Typical clinical features and CT or MRI brain findings help to differentiate DDMS from similar conditions.
Because of limited experience in pediatrics, treatment guidelines for DDMS have not been clearly developed yet. ${ }^{8}$ Our patient has been managed with carbamezepine to control seizure and physiotherapy to improve motor ability of right limbs.

In conclusion, DDMS should be considered in a child with hemiplegia, facial asymmetry, seizures, developmental delay or mental retardation. Diagnosis is possible with typical clinical features and CT or MRI brain findings.

\section{REFERENCES}

1. Aguiar PH, Liu CW, Leitho H, Issa F, Lepski G, Figueiredo EG, Piato FG et al. MR and CT imaging in the Dyke-DavidoffMasson syndrome. Arg Neuropsiquiatr. 1998;56(4):803-07.

2. Zilkha A. CT of cerebral hemiatrophy. AJR. 1980;135:259-62.

3. Dyke CG, Davidoff LM, Masson CB. Cerebral hemiatrophy with homolateral hyperatrophy of the skull and sinuses. Surg Gyn Obstet. 1933;57:588-600.

4. Sener RN, Jinkins JR. MR of craniocerebral hemiatrophy. Clin Imaging. 1992;16:93-97.

5. Ono K, Komai K, Ikeda T. Dyke- Davidoff- Masson syndrome manifested by seizure in late childhood: a case report. J Clin Neurosci. 2003;10:367-71.
6. Unal O, Kiymaz N, Dilek I, Kayan M, Anlar O. Cerebral hemiatrophy associated with hematological and developmental disorders. Journal of Pediatric neurology. 2004; 2(3):169-72.

7. Giovedi. Neuroradiology on the net (intranet) yke-Davidoff-Masson Syndrome (DDMS) August 2009, from http://neuroradiologyonthenet.blogspot.com/2009/08.

8. Lee JH, Lee ZI, Kim HK, Kwon SH. A case of Dyke-DavidoffMasson syndrome in Korea. Korean J Pediatr. 2006;49(2):208211. 